\title{
Primary malignant mixed müllerian tumor of the peritoneum a case report with review of the literature
}

\author{
Fisnik Kurshumliu', Helle Rung-Hansen², Vibeke Ravn Skovlund³ ${ }^{3}$ Lumturije Gashi-Luci', Thomas Horn³*
}

\begin{abstract}
Malignant mixed Müllerian tumor is a rare malignancy of the genital tract and extremely uncommon in extragenital sites. This report describes a case of malignant mixed Müllerian tumor arising in the lower peritoneum of a 72-year-old female patient. The patient presented with ascites, lower abdominal mass and pleural effusion. The serum level of CA125 was elevated. At operation a diffuse carcinosis associated with tumor mass measuring $20 \times$ $15 \times 10 \mathrm{~cm}$ in the vesicouterine and Duglas' pouch were found. The uterus and the adnexa were unremarkable. Histopathology revealed a typical malignant mixed Müllerian tumor, heterologous type. The epithelial component was positive for cytokeratin 7 and vimentin whereas the mesenchymal component was positive for Vimentin, S100 and focally for CK7. The histogenesis of this tumor arising from the peritoneum is still speculative. Based on the previous reports and the immunohistochemical analysis of our case, we believe that this is a monoclonal tumor with carcinoma being the "precursor" element. Nevertheless, further molecular and genetic evidence is needed to support such a conclusion.
\end{abstract}

\section{Background}

Malignant mixed Müllerian tumor (MMMT) is a rare entity that arises from structures that are embryologically related to the Müllerian system [1,2]. The usual location of MMMT is the female genital tract. Extragenital origin is extremely rare [3-5]. Histologically and by immunohistochemistry, the tumor exhibits both epithelial and mesenchymal components.

Since the first report in 1955 by Ober and Black [5], to our knowledge there have been only 30 well documented reports of extragenital malignant mixed Müllerian tumors [6-15]. This prompted us to report on a tumor with primary peritoneal location and to review the relevant existing literature.

\section{Case Report}

A 72-year-old woman, with unremarkable gynaecological history presented with chest pain and dyspnoea, increasing in intensity over the last three weeks. A chest X-ray showed pleural effusion and the subsequent fine needle

\footnotetext{
* Correspondence: thoho@herlevhosp.kbhamt.dk

${ }^{3}$ Institute of Anatomic Pathology, Herlev University Hospital, Copenhagen, Denmark

Full list of author information is available at the end of the article
}

aspiration cytology revealed malignant epithelial cells. The serum level of CA125 was $712 \mathrm{U} / \mathrm{ml}$.

CT scan of abdomen and chest revealed ascites and pleural effusion but no tumor mass. Pelvic ultrasonography, however, revealed excrescences adjacent to the interior surface of the abdominal wall and tumor load in the lower part of abdomen. The uterus and the right ovary were described as normal; the left ovary was not visualised.

An ultrasound-guided biopsy from the tumor reported a carcinosarcoma (see later).

The patient underwent exploratory laparotomy. A widely spread peritoneal carcinosis and a tumor measuring $20 \times 15 \times 10 \mathrm{~cm}$ in the vesicouterine and Duglas' pouch were found.

Biopsy samples were taken from the tumor as well as from the serosa of the urinary bladder. Also, complete hysterectomy with partial omentectomy was performed. There was no suspicion of intrahepatic metastasis. Gallbladder, stomach, pancreas and appendix were unremarkable.

Histopathology was consistent with the diagnosis of a primary peritoneal malignant mixed Müllerian tumor given that the uterus and the adnexa were unremarkable.

\section{(Ciomed Central}


Postoperatively, the patient underwent chemotherapy (Carboplatin in doses of $468 \mathrm{mg} / 360 \mathrm{mg}$ every third week, as it was not felt that the patient was fit for more aggressive treatment). The disease progressed despite treatment and subsequent introduction of Treosulfan.

The patient passed away 12 months after diagnosis. No autopsy was performed.

\section{Material and methods}

\section{Gross pathology}

The tumor tissue submitted for pathology were fragmented, irregular tissue masses measuring altogether 16 $\times 12 \times 4.5 \mathrm{~cm}$. All the fragments were tan-white, irregular fleshy masses with areas of necrosis and hemorrhage.

The uterus and the Fallopian tubes were unremarkable. The right and the left ovary were of normal dimensions. Numerous sections were taken from the tumor as well as from the uterus and adnexa.

\section{Histology and Histochemistry}

The tissue was fixed in 10\% neutral buffered formalin $(\mathrm{pH} 7,0)$, routinely processed, and embedded in paraffin using standard methods. Four-micrometer sections were stained with hematoxylin and eosin, Periodic acid-Schiff (PAS) with diastase predigestion, and Alcian/PAS.

\section{Immunohistochemistry}

Formalin-fixed, paraffin-embedded tissue was stained with the peroxidase method using the EnVision visualisation system (Additional file 1).

\section{Results}

\section{Histology and histochemistry}

Most of the tumor tissue had the characteristics of poorly differentiated carcinoma (Figure 1). There was no

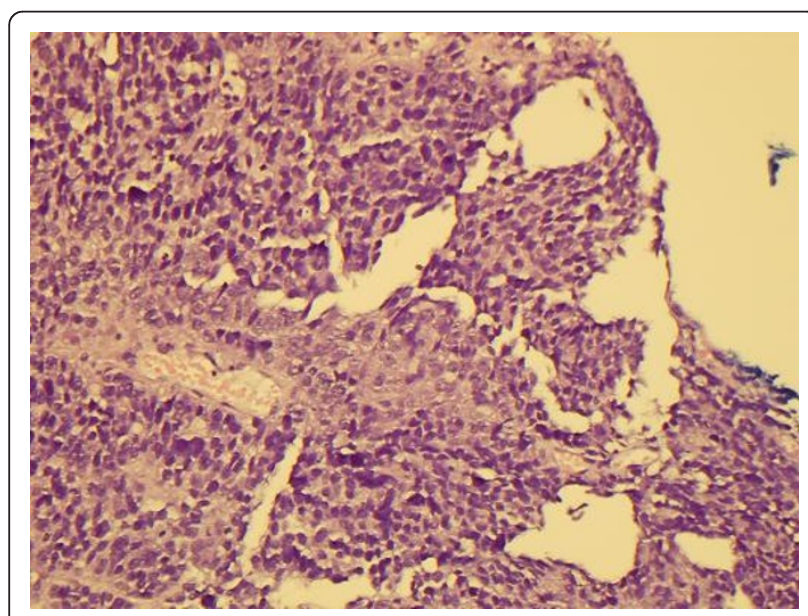

Figure 1 Histological picture showing the admixed carcinoma and spindle cell sarcomatous elements (HE $\times 200$ ).

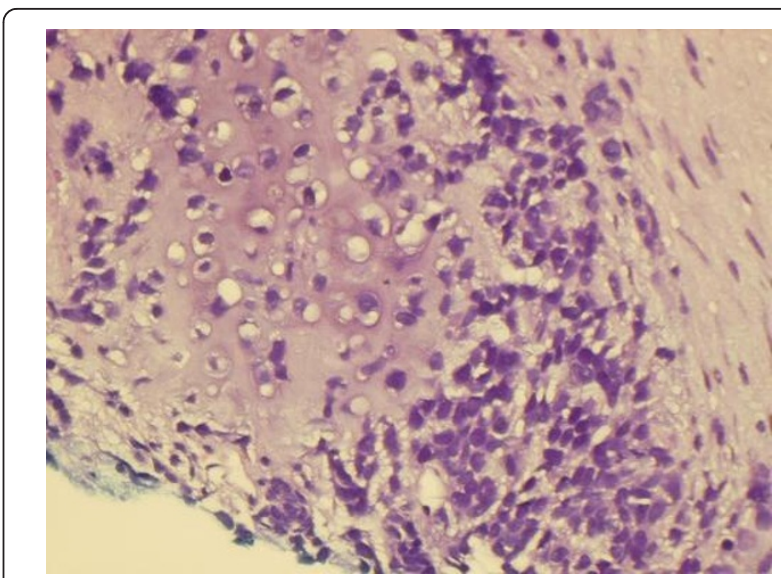

Figure 2 Histological picture showing malignant cartilage admixed with sheets of undifferentiated spindle cells (HE $\times$ 400).

squamous cell or glandular differentiation. The mesenchymal component was composed of sheets of undifferentiated spindle cells and areas of cartilage (Figure 2).

Numerous sections from the uterus and the adnexae showed no evidence of tumor.

\section{Immunohistochemistry}

Immunohistochemical staining for cytokeratin 7 decorated cells of the epithelial component and scattered cells within the mesenchymal component (Figure 3 and Figure 4). Vimentin was strongly positive in mesenchymal component and sporadicaly in the epithelial areas (Figure 5). Cytokeratin 20 and calretinin were negative in both epithelial and mesenchymal elements.

\section{Discussion and the review of Literature}

Malignant mixed Müllerian tumor (MMMT) is a highly aggressive tumor consisted of malignant

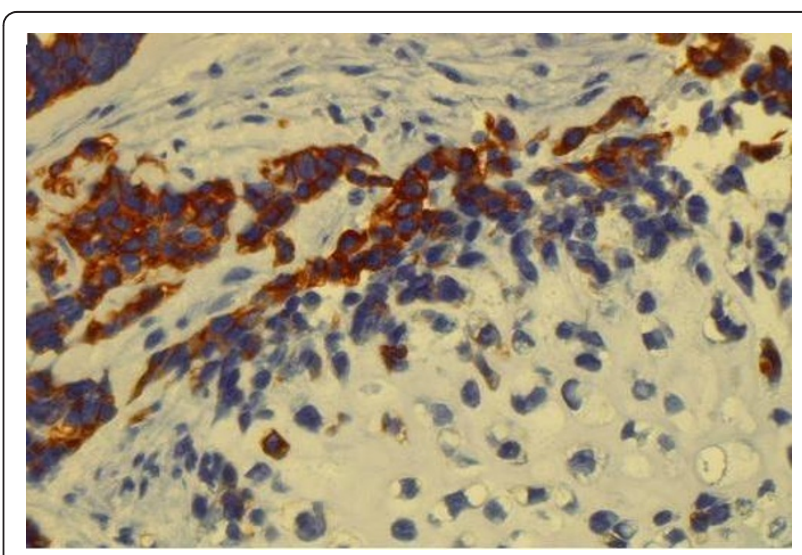

Figure 3 Immunohistochemical stain with Cytokeratin 7 shows strong immunoreactivity of the undifferentiated epithelial cells $(\times 400)$ 


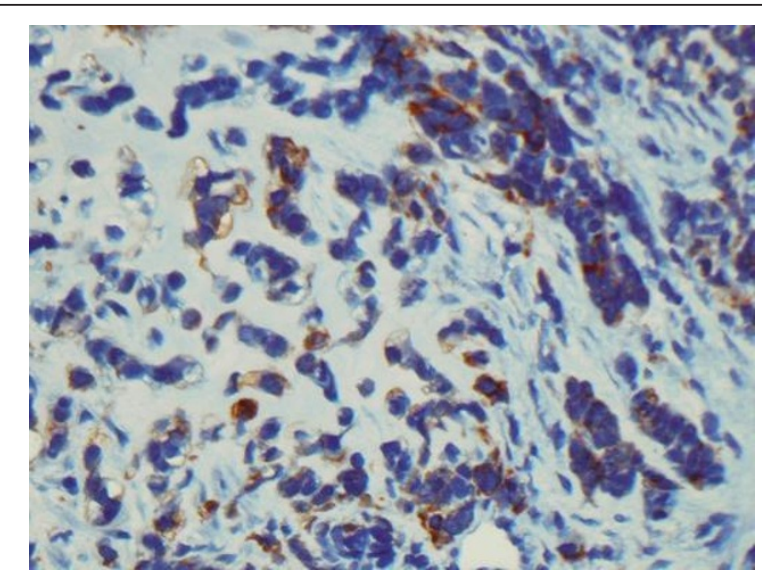

Figure 4 Immunohistochemical stain with Cytokeratin 7 shows scattered Cytokeratin 7-positive cells in the mesenchymal component $(\times 400)$

epithelial and stromal cells. MMMTs were traditionally regarded as a subtype of uterine sarcomas or a mixture of true carcinoma and sarcoma, however several reports suggested a monoclonal origin of these tumors [1-3] Interestingly, molecular data published by Wada and co-workers [4] suggested that although most carcinosarcomas are combination tumors, some develop as collision tumors.

The morphology of the present tumor is consistent with malignant mixed Müllerian tumor. The epithelial component exhibited positivity for cytokeratin 7 and Vimentin and was negative for Cytokeratin 20. Moreover, the mesenchymal component was diffusely positive for Vimentin, focally for CK 7 and exhibited areas of heterologous malignant cartilage.

The primary peritoneal location and origin was confirmed after thorough gross and microscopic

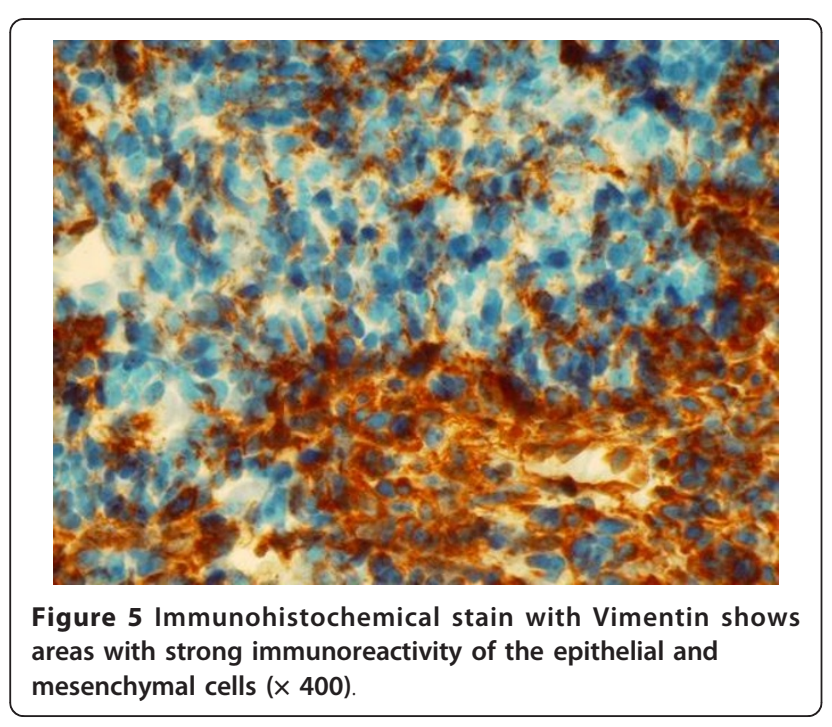

examination of the uterus and adnexae. Furthermore, absence of calretinin expression suggested that the tumor was of Müllerian rather than pure mesothelial origin [6]. A search of the literature revealed 30 previously reported cases of extragenital MMMT (Additional file 2) with the majority of the patients being in the postmenopausal age [5-19]. Twenty-two of the reported cases were of primary peritoneal origin and most of them arose in the pelvis [19]. Thirteen were heterologous type [19].

In the homologous type MMMT, mesothelioma would rightfully be considered as a possibility [6]. However, in this case a positive reaction of the cells to Calretinin would be expected [6]. Immunoreactivity of the epithelial cells to Cytokeratin 7 and negative reaction for cytokeratin 20 also points toward Müllerian origin. A theoretical possibility is of course the origin in endometriosis or endosalpingiosis. However, although impossible to rule out, the lack of demonstrable endometriosis associated with the patient's current tumor makes this hypothesis unlikely [16].

Several theories have emerged in the attempt to explain the biphasic appearance of the tumor, the most important of which are the "collision", "conversion" and the "combination" theory [1]. Sternberg et al. [20] was the first to suggest the conversion, stating that sarcomatous elements may develop from carcinoma. They described a case of metastatic heterologous type carcinosarcoma of the omentum with primary endometrial origin. There was no evidence of sarcoma component in the primary tumor. From that time onward, a number of cases with metachronous or synchronous gynaecologic carcinoma have been reported $[11,14,16]$. Masuda et al. [21] further supported the conversion theory with their study in which cell lines established from malignant mixed Müllerian tumors showed the ability of the epithelial tumor cells to transform into epithelial, mesenchymal or both types of differentiation in vitro, while the mesenchymal cells did not show similar capabilities.

MMMT has a poor prognosis with most of the patients following a rapidly fatal course regardless of the initial tumor stage [9]. A review done by Garamvoelgyi et al. [14] showed that most patients passed away within one year with median postoperative survival time being 14 months. Due to the rarity of the disease, limited data regarding the management of peritoneal MMMT exist. Treatment modalities include surgery, chemotherapy and irradiation with various survival outcomes. Ko et al. [19] reported on a patient that was treated with optimal tumor debulking and a combination of chemotherapy with Ifosfamide and Cisplatin, followed by pelvic irradiation. There were no signs of recurrence for 48 months and was the case with the longest disease-free survival in the reported literature. 


\section{Conclusion}

Based on the ample evidence of the previous reports, and the immunohistochemical analysis of our case, we believe that this is a monoclonal tumor with the carcinoma being the "precursor" element. Nevertheless, further molecular and genetic evidence is needed to support such a conclusion.

\section{Consent}

Informed consent was obtained from the patient for publication of this case report and accompanying images.

\section{Additional material}

Additional file 1: Immunohistochemical stains

Additional file 2: Primary peritoneal MMMT reported in the literature.

\section{Author details}

${ }^{1}$ Institute of Anatomic Pathology, Medical School, University Clinical Center, Prishtina, Kosovo. ${ }^{2}$ Department of Gynecology and Obstetrics, Herlev University Hospital, Copenhagen, Denmark. ${ }^{3}$ Institute of Anatomic Pathology, Herlev University Hospital, Copenhagen, Denmark.

\section{Authors' contributions}

FK prepared the manuscript and reviewed the literature. HRH provided the clinical data. VRH reviewed the slides, LGL reviewed the manuscript, TH reviewed the slides and supervised the preparation of the manuscript.

\section{Competing interests}

The authors declare that they have no competing interests.

Received: 2 May 2010 Accepted: 4 February 2011

Published: 4 February 2011

\section{References}

1. McCluggage WG: Malignant biphasic uterine tumours: carcinosarcomas or metaplastic carcinomas? J Clin Pathol 2002, 55:321-325.

2. Mayall $F$, Rutty $K$, Campbell $F$, Goddard H: p53 immunostaining suggests that uterine carcinosarcomas are monoclonal. Histopathology 1994, 24(3):211-214.

3. Watanabe M, Shimizu K, Kato H, Imai H, Nakano H, Sugawa M, Shiraishi T: Carcinosarcoma of the uterus: immunohistochemical and genetic analysis of clonality of one case. Gynecol Oncol 2001, 82(3):563-567.

4. Wada H, Enomoto T, Fujita M, Yoshino K, Nakashima R, Kurachi H, Haba T, Wakasa K, Shroyer KR, Tsujimoto M, Hongyo T, Nomura T, Murata Y: Molecular evidence that most but not all carcinosarcomas of the uterus are combination tumors Cancer Res. 1997, 57:5379-5385.

5. Ober WB, Black MB: Neoplasms of the subcoelomic mesenchyme: report of two cases. Arch Pathol 1955, 59:698-705.

6. Sumathi VP, Murnaghan M, Dobbs SP, McCluggage WG: Extragenital Müllerian carcinosarcoma arising from the peritoneum: report of two cases. Int J Gynecol Cancer 2002, 12:764-767.

7. Lauchlan SC: The secondary Müllerian system. Obstet Gynecol Surg 1972, 27:133-146.

8. Zelmanowicz A, Hildesheim A, Sherman ME, Sturgeon SR, Kurman RJ, Barrett RJ, Berman ML, Mortel R, Twiggs LB, Wilbanks GD, Brinton LA: Evidence for a common etiology for endometrial carcinomas and malignant mixed Müllerian tumors. Gynecol Oncol 1998, 69:253-257.

9. Friedrich $M$, Villena-Heinsen $C$, Mink D, Bonkhoff $H$, Schmidt W: Carcinosarcoma, endometrial intraepithelial carcinoma and endometriosis after tamoxifen therapy in breast cancer. Eur $\mathrm{J}$ Obstet Gynecol 1999, 82:85-87.

10. Nascimento MC, Choo PS, Bligh J, Obermair A: Primary peritoneal malignant mixed Müllerian tumor (MMMT): a case report. Cancer Therapy 2004, 2:571-574

11. Shen DH, Khoo US, Xue WC, Ngan HYS, Wang JL, Liu WWS, Chan YK, Cheung ANY: Primary peritoneal malignant mixed Müllerian tumors: a clinicopathologic, immunohistochemical and genetic study. Cancer 2001, 91:1052-1060.

12. Shintaku M, Matsumoto T: Primary Müllerian carcinosarcoma of the retroperitoneum: report of a case. International J Gynecol Pathol 2001, 20:191-195.

13. Ibanez-Manlapaz IG, McCoy D, Vincent V III, Ule UJ: Malignant mixed Müllerian tumor of the extra-genital coelomic epithelium: report of two cases. Pathology Oncology Research 1997, 3:130-134.

14. Garamvoelgyi E, Guillou I, Gebhard S, Salmeron M, Seematter RJ, Hadji MH: Primary malignant mixed Müllerian tumor (metaplastic carcinoma) of the female peritoneum. Cancer 1994, 74:854-863.

15. Choong SYM, Scurry JP, Planner RS, Grant PT: Extrauterine malignant mixed Müllerian tumor of primary peritoneal origin. Pathology 1994, 26:497-498.

16. Garde JR, Jones MA, McAfee R, Tarraza HM: Extragenital malignant mixed Müllerian tumor. Gynaecol Oncol 1991, 43:186-190.

17. Weisz-Carrington P, Bigelow B, Schinella RA: Extragenital mixed heterologous tumor of Müllerian type arising in the cecal peritoneum: report of a case. Dis Colon Rectum 1977, 20(4):329-333

18. Hasiuk AS, Petersen RO, Hanjani P, Griffin TD: Extragenital malignant mixed Müllerian tumor: case report and review of the literature. Am J Clin Pathol 1984, 81:102-105.

19. Ko ML, Jeng CJ, Huang SH, Shen J, Tzeng CR, Chen SC: Primary peritoneal carcinosarcoma (malignant mixed Müllerian tumor): Report of a case with five-year disease free survival after surgery and chemoradiation and a review of literature. Acta Oncologica 2005, 44(7):756-760.

20. Sternberg WH, Clark WH, Smith RC: Malignant mixed Müllerian tumor (malignant mixed mesodermal tumor) of the uterus: a study of 21 cases. Cancer 1954, 7:704-724

21. Masuda A, Takeda A, Fukami H, Yamada C, Matsuyama M: Characteristics of cell lines established from mixed mesodermal tumor of the human ovary: carcinomatous cells are changeable to sarcomatous cells. Cancer 1987, 60:2969-2703.

doi:10.1186/1477-7819-9-17

Cite this article as: Kurshumliu et al:: Primary malignant mixed müllerian tumor of the peritoneum a case report with review of the literature. World Journal of Surgical Oncology 2011 9:17

\section{Submit your next manuscript to BioMed Central and take full advantage of:}

- Convenient online submission

- Thorough peer review

- No space constraints or color figure charges

- Immediate publication on acceptance

- Inclusion in PubMed, CAS, Scopus and Google Scholar

- Research which is freely available for redistribution 